\title{
Megalencephalic Leukoencephalopathy with Subcortical Cysts
}

\author{
Ranjana Gupta ${ }^{1}$, Akshay Kumar², Narender Yadav³, Simar Abheet Singh" ${ }^{4}$ Puneet Mittal ${ }^{5}$
}

1Department of Radiodiagnosis, Maharishi Markandeshwar Institute of Medical Sciences and Research (MM

Deemed to be University), Mullana, Ambala, Haryana, India. ${ }^{2}$ Department of Radiodiagnosis, Maharishi

Markandeshwar Institute of Medical Sciences and Research (MM Deemed to be University), Mullana, Ambala,

Haryana, India. ${ }^{3}$ Department of Radiodiagnosis, Maharishi Markandeshwar Institute of Medical Sciences and

Research (MM Deemed to be University), Mullana, Ambala, Haryana, India. ${ }^{4}$ Department of Radiodiagnosis,

Maharishi Markandeshwar Institute of Medical Sciences and Research (MM Deemed to be University), Mullana,

Ambala, Haryana, India. ${ }^{5}$ Department of Radiodiagnosis, Maharishi Markandeshwar Institute of Medical

Sciences and Research (MM Deemed to be University), Mullana, Ambala, Haryana, India.

\section{INTRODUCTION}

Megalencephalic Leukoencephalopathy is a rare entity which was first described by Van Der Knaap et al in 1995.[1] It is a progressive neurodegenerative disorder characterized by slow progression of mental deterioration. Megalencephaly sets in early in the disease usually in first year and can be more than 4 standard deviation above the mean. Seizures are present in almost all the patients. [2] We present typical MRI findings in a case of megalencephalic leukodystrophy with sub-cortical cysts.

Megalencephalic leukoencephalopathy with sub-cortical cysts is a rare entity that presents with macrocephaly and seizures. Mental deterioration is often mild with slow progression. Macrocephaly may be present at birth or develops in first year. Typical magnetic resonance imaging (MRI) findings help to clinch the diagnosis.

\section{PRESENTATION OF CASE}

A 12-year-old male patient presented with long history of generalised tonic clonic seizures, frequent falls and decreased school performance. On physical examination his head size was enlarged. MRI (Figure 1A-C) revealed abnormal signal in bilateral subcortical white matter appearing hyperintense on T2W and hypointense on T1W images. Cysts were seen in bilateral anterior temporal subcortical white matter. The boy belonged to Aggarwal ethnic community. Based on the characteristic clinical background and MR findings, diagnosis of Megalencephalic leukoencephalopathy with subcortical cysts was made.

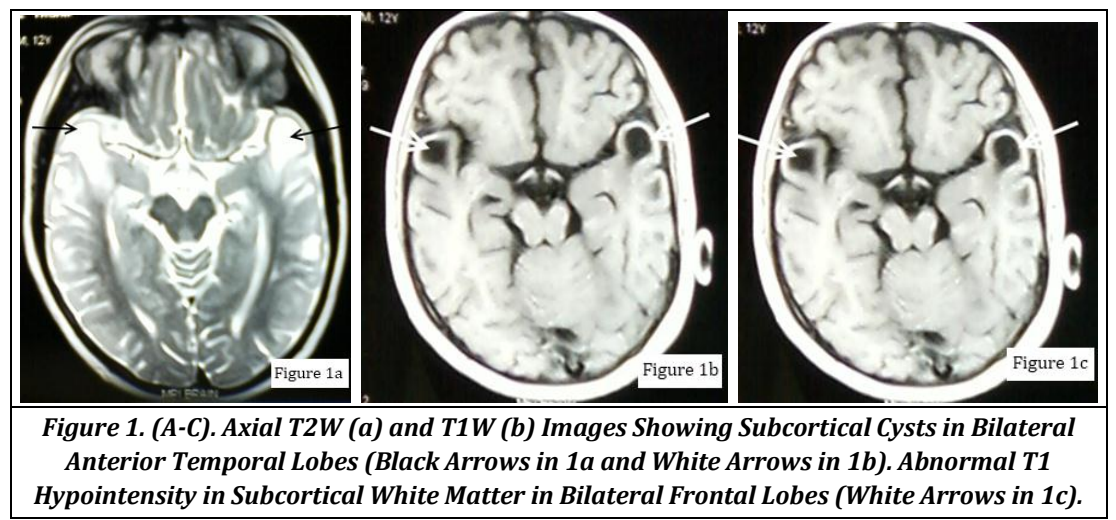

Corresponding Author:

Akshay Kumar,

Department of Radiodiagnosis,

Maharishi Markandeshwar Institute of

Medical Sciences and Research

(MM Deemed to be University),

Mullana, Ambala, Haryana, India.

E-mail:drakirads@gmail.com

DOI: $10.14260 / \mathrm{jemds} / 2020 / 103$

Financial or Other Competing Interests: None.

How to Cite This Article:

Gupta R, Kumar A, Yadav $N$, et al. Megalencephalic leukoencephalopathy with subcortical cysts. J. Evolution Med. Dent. Sci. 2020;9(07):458-459, DOI: 10.14260/jemds/2020/103

Submission 30-11-2019,

Peer Review 20-01-2020,

Acceptance 28-01-2020,

Published 17-02-2020.

\section{(i)}




\section{DISCUSSION}

Initially it presents with macrocephaly in the first year of life which may normalise later on. Initially development is deceptively normal. However, with time, there is slow motor and mental deterioration. Seizures and extrapyramidal symptoms such as dystonia and athetosis may also be seen. There is only mild cognitive impairment. [2-4] On MR imaging, initially there is swelling of the subcortical white matter which progresses to characteristic subcortical cysts which are more prevalent in temporal lobes. There is relative sparing of central grey matter structures and brainstem. Characteristic MRI findings are sufficient for the diagnosis. $[5,6]$ Over time, there is progressive enlargement of the size of the cysts and loss of white matter volume. Since its first description in 1995, many cases have been reported in the literature. Largest of them belong to Aggarwal community in India.[6,7] It is an autosomal recessive disorder. Clinical course may be static or slowly progressive. ${ }^{[4]}$ There is no effective treatment. Antiepileptic's and physical therapy are the mainstay of the treatment.

\section{CONCLUSIONS}

Megalencephalic leukoencephalopathy with subcortical cysts is a rare condition. It should be suspected in any child with progressive neurological deficit and macrocephaly, especially those belonging to Aggarwal community. Awareness of characteristic MRI findings helps to clinch the diagnosis.

\section{REFERENCES}

[1] Van der Knaap MS, Barth PG, Stroink H, et al. Leukoencephalopathy with swelling and a discrepantly mild clinical course in eight children. Ann Neurol 1995;37(3):324-34.

[2] Rajagopal KV, Ramakrishnaiah RH, Avinash KR, et al. Van der Knaap disease, a megalencephalic leukoencephalopathy. Indian J Radiol Imaging 2006;16(4):733-4.

[3] Joseph E, Sureka J, Gibikote S, et al. Megalencephalic leukoencephalopathy with subcortical cysts in an adult. Acta Neurol Belg 2009;109(1):53-4.

[4] Park EY, Kim YO, Kim JY, et al. A case of megalencephalic leukoencephalopathy with subcortical cysts. Korean Journal of Pediatrics 2008;51(12):1342-5.

[5] Boor PKI, de Groot K, Mejaski-Bosnjak V, et al. Megalencephalic leukoencephalopathy with subcortical cysts: an update and extended mutation analysis on MLC1. Hum Mutat 2006;27(6):505-12.

[6] Sethi PK, Sethi NK. Megalencephalic leukoencephalopathy with subcortical cysts. Indian J Pediatr 2004;71(5):473-5.

[7] Singhal BS, Gorospe JR, Naidu S. Megalencephalic leukoencephalopathy with subcortical cysts. J Child Neurol 2003;18(9):646-52. 